\title{
Analisis Teknik Pertandingan Kumite Dalam Olahraga Beladiri Karate
}

\author{
Kaleb Zebua, David Siahaan \\ Fakultas Ilmu Keolahragaan, Universitas Negeri Medan \\ kalebzebua@gmail.com,dd9han@gmail.com
}

\begin{abstract}
Abstrak: Penelitian ini bertujuan untuk mengetahui performa penampilan atlet dalam suatu pertandingan melalui video pertandingan karate kumite pada Sea Games Ke-29 Tahun 2017 di Kuala Lumpur, Malaysia menggunakan aplikasi klipdraw. Pada kategori final putra dibawah $55 \mathrm{~kg}$ pertandingan dimenangkan oleh Iwan Bidu Sirait dari Indonesia dengan perolehan point sebanyak 10 yang terdiri dari 7 pukulan dan 1 tendangan. Adapun jumlah pukulan yang dilakukan selama pertandingan adalah 16 dengan 7 pukulan yang menghasilkan point sehingga persentase keberhasilan pukulannya adalah 44\%. Tendangan yang dilakukan selama pertandingan sebanyak 14 dengan 1 tendangan yang menghasilkan point sehingga persentase keberhasilan tendangannya adalah $8 \%$. Sedangkan John Paul Bejar dari Filipina menghasilkan point sebanyak 4 yang semuanya dihasilkan oleh pukulan. Adapun jumlah pukulan yang dilakukan selama pertandingan adalah 13 dengan persentase keberhasilan 24\%. Sedangkan jumlah tendangan yang dilakukan adalah 9 dimana tidak ada menghasilkan point atau persentase keberhasilan tendangan tersebut adalah 0\%. Pada kategori final putri dibawah $50 \mathrm{~kg}$ hasil pertandingan dimenangkan oleh Srunite Sari Sukatendel karateka putri dari Indonesia dengan perolehan point sebanyak 6 yang terdiri dari 3 pukulan dan 1 tendangan adapun jumlah pukulan yang dilakukan selama pertandingan berlangsung adalah 13 dengan 3 pukulan yang dapat menghasilkan point adapun persentase keberhasilan adalah $19 \%$ sedangkan jumlah tendangan yang dilakukan adalah 9 dan hanya 1 tendangan yang menghasilkan point dengan persentase keberhasilan $11 \%$. Sedangkan Paweena Raksachart Karateka Putri dari Thailand tidak menghasilkan point selama pertandingan berlangsung. Terdapat 19 pukulan yang dilakukan dan 8 tendangan dimana tidak satupun yang dapat menghasilkan point atau persentase keberhasilannya adalah $0 \%$.
\end{abstract}

Kata Kunci : Karate, Kumite, Analisis Pertandingan

\section{Analysis of Kumite Techniques in Karate Competition}

Abstract: This study aims to determine the performance of athletes in a match through a video of a karate kumite competition at the 29th Sea Games in 2017 in Kuala Lumpur, Malaysia which was assisted by using the clip draw application. In the men's final category under $55 \mathrm{~kg}$, the match was won by Iwan Bidu Sirait from Indonesia with 10 points consisting of 7 punches and 1 kick. The number of strokes made during the match was 16 with 7 strokes which resulted in points so that the percentage of successful strokes was 44\%. The kicks taken during the match were 14 with 1 kick that resulted in points so that the percentage of successful kicks was $8 \%$. Meanwhile, John Paul Bejar from the Philippines produced 4 points, all of which were generated by punches. The number of strokes made during the match is 13 with a success percentage of 24\%. While the number of kicks taken is 9 where there are no points or the percentage of successful kicks is $0 \%$. In the women's final category under $50 \mathrm{~kg}$, the result of the match was won by Srunite Sari Sukatendel female karateka from Indonesia with 6 points consisting of 3 strokes and 1 kick while the number of strokes taken during the match was 13 with 3 strokes which could result in points as for the percentage success is 19\% while the number of kicks taken is 9 and only 1 kick results in a point with a success percentage of $11 \%$. Meanwhile, Paweena Raksachart Karateka Putri from Thailand did not produce any points during the match. There were 19 punches and 8 kicks, none of which resulted in a point or the percentage of success was $0 \%$.

Keywords: Karate, Kumite, Competition Analysis 


\section{PENDAHULUAN}

Beladiri karate mencakup tiga bahagian besar teknik yang telah dikelompokkan yaitu kata, kumite dan kihon. Teknik dasar atau disebut dengan kihon yang meliputi pukulan (tsuki), tangkisan (uke), tendangan (geri) dan kuda-kuda (dachi). Beberapa jenis kuda-kuda (dachi) yang di pelajari dalam karate adalah hachiji-dachi, zen-kutsu-dachi, ko-kutsu-dachi, hangetsu-dachi, heisoku-dachi, neko-ashi-dachi, sanshin-dachi, sochin-dachi. Pukulan (Zuki) dalam Karate terdiri dari oi-zukichudan, oi-zuki-jodan, kisame-zuki, gyaku-zuki, ura-zuki, soto-ude-uke, morote-zuki, agi-zuki, chokuzuki, hachiji-dachi), kage-zuki, yama-zuki, morote-hisame-zuki, tetsui-uchi, uraken-uchi, haishu-uchi. Adapun tendangan atau geri terdiri dari mae-geri, mawashi-geri, yoko-geri-kekome, yoko-geri-keange, usiro-geri. Sedangkan tangkisan dalam karate antara lain gedan barai, soto-ude-uke, uchi-ude-uke, agi-uke, shuto-uke, juji-uke, morote-uke (M. Nakayama, 2010;79).

Kihon adalah teknik dasar dari beladiri karate dimana rangkaian dari kihon menjadi sebuah kata atau pola atau bentuk perpaduan dari beberapa gerakan kihon sehingga menunjukkan gerakan dengan irama yang indah. Setiap paduan gerakan dari kata tidak hanya mengandung gerakan fisik mulai dari tangan, kaki dan seluruh bahagian tubuh tetapi juga memiliki filosofi yang memberikan pengertian yang perlu dipahami oleh setiap karateka. Kata dalam karate dan seluruh teknik dasar yang telah dikombinasi dalam urutan dalam kata telah disempurnakan dan dikembangkan melalui pengalaman dan latihan oleh para pendahulu atau pencipta dari karate itu sendiri. Kumite adalah salah satu teknik pertarungan dalam karate dimana setiap karateka bertarung saling pukul dan tangkis. Pertandingan karate, digunakan berbagai macam serangan seperti pukulan (tsuki) dan tendangan (geri) untuk mendapatkan nilai yang sebanyak-banyaknya agar dapat memenangkan suatu pertandingan sedangkan untuk menghindari serangan dapat dilakukan dengan tangkisan (uke).

Kumite secara harfiah dapat diartikan sebagai "pertemuan tangan". Kumite adalah suatu metode latihan yang menggunakan teknik serangan dan teknik bertahan diaplikasikan melalui pertarungan dengan lawan yang saling berhadapan (Prihastono, 1995:46). Kumite adalah suatu metode latihanlatihan teknik dasar pukulan, tangkisan, dan tendangan. Kumite dilakukan oleh murid-murid tingkat lanjut (sabuk biru atau lebih). Sebelum melakukan kumite bebas (jiyu kumite) praktisi mempelajari kumite yang diatur (go hon kumite). Sujoto (2002: 152) menyatakan latihan kumite terdiri dari tiga bentuk, yaitu: pertarungan dasar (kihon kumite), pertarungan satu teknik (kihon ippon kumite), dan pertarungan bebas (jiyu kumite). Pada latihan kihon kumite dan latihan kihon ippon kumite semua teknik serangan, teknik tangkisan, dan teknik serangan balasan telah ditentukan sebelumnya. Namun, latihan jiyu kumite tidak ada pengaturan teknik sebelumnya, hal ini dikarenakan setiap karateka bebas menggunakan kemampuan teknik yang dimiliki. Pertandingan kumite (kumite shiai) yang saat ini resmi dipertandingkan merupakan salah satu bentuk latihan kumite dalam bentuk latihan pertarungan bebas (jiyu kumite). Atlet yang akan melakukan jiyu kumite tetap harus mengontol pukulan, tendangan, dan serangan sehingga tidak benar-benar mengenai titik vital lawan.” (M. Nakayama, 2010: 112-113).

Seorang karateka harus cepat dan jeli untuk melihat serangan yang datang dan melihat kesempatan untuk melakukan serangan dimana hal ini menjadi salah satu penentu kemenangan pada saat melakukan tanding kumite. Adapun teknik-teknik yang digunakan dalam kumite karate antara lain kuda-kuda, pukulan, tendangan dan juga tangkisan. Pukulan merupakan teknik serangan menggunakan tangan, teknik ini sering digunakan karateka karena memiliki kecepatan hingga mengenai sasaran. Tendangan mempunyai keistimewaan dalam suatu pertandingan kumite karate. Teknik tendangan yang dilancarkan oleh karateka yang masuk dan tepat pada sasaran mendapatkan nilai yang lebih besar daripada teknik pukulan yang tepat pada sasaran yang dapat menghasilkan nilai. Chung-Yu Chen \& Huang Chenfu (2008) menjelaskan bahwa keterampilan menendang memiliki keterkaitan dengan jarak dan kesesuaian target. Pada pertandingan karate, karateka menggunakan teknik tendangan dengan berbagai variasi untuk mendapatkan kemenangan atau membalikkan keadaan, dari keadaan tertinggal nilai menjadi unggul.

Berdasarkan pada hasil pertandingan selama ini, pada saat pertandingan kumite, atlet banyak menggunakan teknik pukulan dibandingkan dengan teknik tendangan, dalam pertandingan sendiri atlet akan menggunakan berbagai macam gerakan serangan untuk mendapatkan poin dan memenangkan pertandingan. Tetapi tidak menutup kemungkinan untuk melakukan tendangan pada saat kumite 
dimana tendangan yang tepat sasaran memiliki keunggulan yaitu poin yang lebih tinggi dibandingkan dengan serangan menggunakan pukulan.

Tendangan merupakan senjata untuk menyerang paling jauh jangkauannya dan tenaga yang dihasilkan cukup besar. M. Nakayama (2010:04) menyatakan bahwa dalam kumite terdapat macam penilaian point diantaranya pukulan memperoleh 1 point, tendangan cudhan (bawah) dan tendangan jodhan (atas) memperoleh 3 point. Hasil penelitian Ferry Fendrian dan Muhammad Nurzaman (2016;40) mengatakan bahwa banyak pelatih yang mengatakan bahwa, untuk memenangkan pertandingan kumite hanya cukup dengan menguasai serangan pukulan saja dan ada juga pelatih yang mengatakan serangan tendangan lebih penting dikuasai dengan alasan poin yang didapat lebih besar.

Untuk memenangkan pertandingan karate perlu kiranya dalam pertandingan menggunakan sport science dimana karateka mengetahui statistik pertandingan yang dilakukan oleh lawannya. Hal ini akan memberikan kemudahan untuk menentukan teknik yang akan digunakan pada saat bertanding sehingga dapat memenangkan pertandingan. Dari hasil pengamatan penulis banyak pelatih yang melakukan analisi atletnya hanya melihat dengan kasat mata tanpa adanya data analisis yang kuat melalui pengamatan video dan juga menggunakan aplikasi yang lainnya. Sebaiknya sebelum karateka melakukan pertandingan pelatih dan karateka harus berdiskusi seperti apa kualifikasi lawannya dan karaktersitiknya, pelatih dan karateka sudah mengetahui berapa persentase dan jumlah serangan keseluruhan yang dipakai oleh karateka tersebut seperti tendangan dan pukulan, hingga karakteristik dari serangan dan pukulan tersebut harus dipahami oleh pelatih dan karateka. Sehingga dalam pertandingan karateka sudah bisa mengantisipasi serangan-serangan yang akan terjadi dan juga pola taktik yang digunakan.

Dari pengamatan penulis baik itu di pertandingan karate di tingkat kecamatan, kabupaten hingga propinsi dimana banyak pelatih belum mempunyai data serangan apa saja yang dipakai karateka selama pertandingan itu berlangsung. Bahkan sering kali atlet menggunakan serangan yang tidak perlu digunakan yang mana saat pertandingan berlangsung sering membuang waktu dan energi melakukan serangan yang tidak menghasilkan point sehingga perlu dianalisis bagaimana melakukan serangan yang dapat menghasilkan point. Dengan demikian pelatih memerlukan adanya data analisis serangan kumite yang berguna untuk mengetahui perkembangan atlet mendatang, dapat menjadi bahan evaluasi pelatih untuk atlet teknik mana saja yang harus di tingkatkan ke efesien dan mengukur performa permainan atlet. Diharapkan dengan dilakukannya anlisis pertandingan teknik dalam karate berupa teknik bermain akan mampu membantu mengurangi kendala-kendala yang terjadi saat proses pertandingan maupun latihan. Selain itu juga hasil penelitian ini menjadi dasar bagi pelatih untuk membuat program latihan dimana akan diperoleh data berapa teknik pukulan yang terjadi dan teknik pukulan yang gagal dilakukan. Demikian juga dengan teknik tendangan yang dilakukan oleh karateka. Selain itu hasil dari analisis ini juga menjadi evaluasi bagi pelatih yang melatih karateka itu sendiri sehingga dapat dilakukan perbaikan teknik serangan sehingga bisa lebih baik.

Dalam karate terdapat nomor kata dan kumite yang dipertandingkan dimana kata menampilkan rangkaian gerakan dimana penilaian berupa kebenaran gerakan dan keindahan gerakan yang dilakukan oleh karateka. Sedangkan nomor kumite adalah pertarungan antara dua orang karateka dengan menampilkan teknik-teknik serangan dan tangkisan. Untuk menghindari serangan-serangan yang membuat cedera karateka maka dibuat aturan sehingga tidak terjadi cedera yang berarti pada saat pertandingan berlangsung. Pada pertandingan kumite, kemampuan menguasai teknik dasar secara baik akan menentukan kemenangan yaitu dapat melakukan serangan dengan cepat atau juga melakukan tangkisan dengan benar. Peranan penguasaan akan teknik dalam melakukan serangan dalam pertandingan kumite sangat menentukan perolehan point, teknik serangan yang dilakukan dengan cepat dan tepat kesasaran akan sulit di antisipasi oleh lawan. Teknik serangan dalam pertandingan kumite banyak macamnya diantaranya teknik serangan pukulan, tendangan, pukulan cepat, dan bantingan. Pertandingan karate, digunakan berbagai macam serangan untuk mendapatkan nilai yang sebanyak-banyaknya agar dapat memenangkan suatu pertandingan.

Pertandingan karate tidak hanya sekedar melakukan teknik serangan dan juga tangkisan tentu jika pelatih dan karateka ingin memenangkan pertandingan yang diikuti harus diperhatikan kemampuan dari diri sendiri dan juga kemampuan lawan sehingga dapat dipetakan serangan-serangan yang akan terjadi selama pertandingan berlangsung. Selain itu juga dapat diatur bagaimana serangan yang akan dilakukan sehingga dapat memperoleh point dan juga bagaimana menghindari atau menangkis jika serangan dari lawan datang. Oleh karena itu pelatih dan karateka harus selalu 
melakukan analisis pertandingan sehingga diketahui penggunaan teknik-teknik serangan dan tangkisan baik yang dilakukan oleh lawan juga yang dilakukan oleh karateka itu sendiri.

Analisis pertandingan dilakukan pada step, kuda-kuda, pukulan, tendangan dan tangkisan yang dilakukan karateka selama pertandingan berlangsung. Analisis tersebut dilakukan dengan menghitung jumlah teknik yang dilakukan selama pertandignan berlangsung, jumlah tendangan yang berhasil menghasilkan point dan jumlah tendangan yang gagal menghasilkan point sehingga dapat diperoleh persentase keberhasilan dari serangan yang dilakukan oleh karateka selama pertandingan berlangsung. Kuda-kuda adalah gerakan tumpuan kaki pada saat berdiri dimana posisi kuda-kuda menjadi dasar melakukan serangan yang akan dilakukan karena akan memberikan kemudahan untuk melakukan serangan yang dilakukan. Pukulan adalah teknik serangan dengan menggunakan tangan. Tendangan adalah teknik serangan dengan menggunakan kaki. Tangkisan adalah teknik menghindari serangan baik itu menggunakan tangan maupun bahagian tubuh yang lain. Adapun kerangka berpikir dalam penelitian ini adalah sebagai berikut:

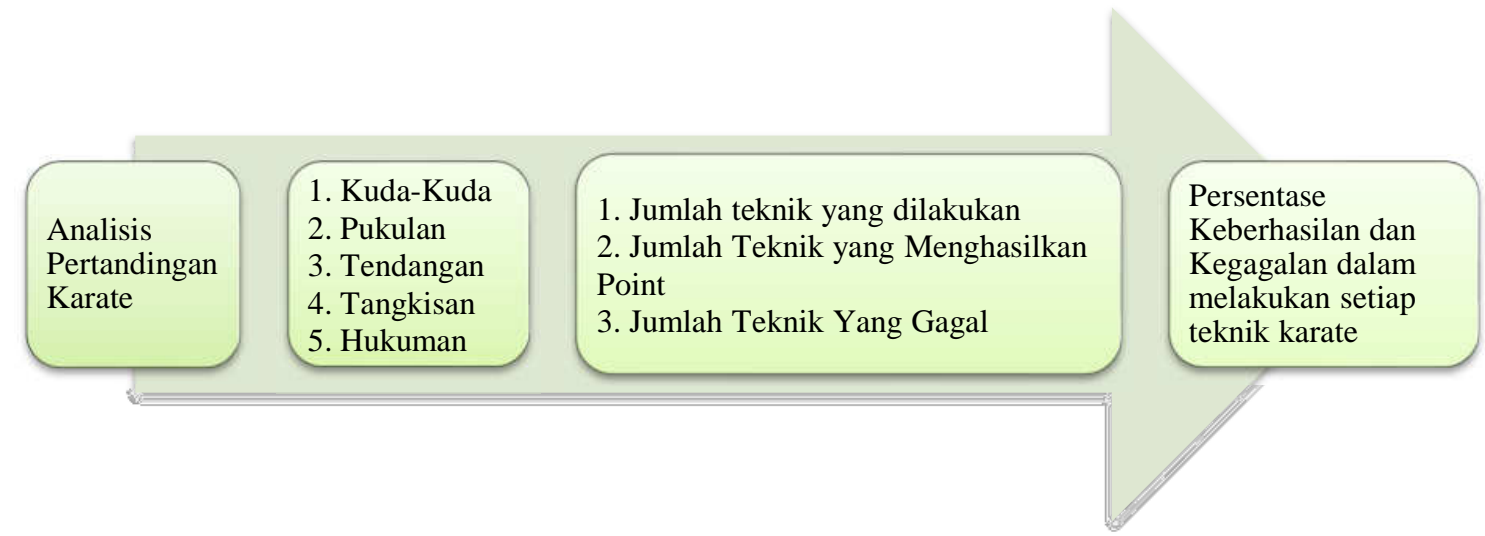

Gambar 1. Kerangka Berpikir Penelitian Analisis Pertandingan Karate

\section{METODE}

Penelitian yang dilakukan berupa penelitian deskritif kuantitatif yaitu menggunakan metode survei. Menurut Arikunto, (2010: 56) bahwa metode survei adalah penyelidikan yang diadakan untuk memperoleh fakta-fakta dari gejala-gejala yang ada dan mencari kekurangan-kekurangan secara faktual. Tujuan penelitian ini untuk mengetahui performa penampilan atlet dalam suatu pertandingan. Analisis dilakukan terhadap hasil pertandingan karate pada saat Sea Games Ke-29 Tahun 2017 di Kuala Lumpur, Malaysia yaitu pada pertandingan final dibawah $55 \mathrm{Kg}$ kategori Putra dan dibawah 50 Kg Putri. Subjek penelitian adalah karateka Indonesia yang masuk final pada Sea Games Ke-29 Tahun 2017 di Kuala Lumpur, Malaysia yaitu pada kategori putra dibawah $55 \mathrm{Kg}$ adalah Iwan Bidu Sirait dari Indonesia yang berhadapan dengan Jhon Paul Bejar dari Philiphina. Sedangkan pada kategori putri dibawah $50 \mathrm{Kg}$ Srunita Sari Sukatendel Dari Indonesia yang berhadapan dengan Paweena Raksachart dari Thailand.

Variabel dalam penelitian ini yaitu analisis teknik kuda-kuda, pukulan, tendangan dan tangkisan yang juga akan menghitung persentase keberhasilan tendangan pukulan dan tangkisan selama pertandingan tersebut berlangsung. Definisi operasionalnya yaitu keberhasilan karateka mendapatkan poin dalam melakukan pukulan, tendangan dan tangkisan yang diukur menggunakan lembar observasi melalui pengamatan dari video pertandingan dengan menggunakan aplikasi klip draw.

Arikunto (2010:149), instrumen penelitian adalah alat dan fasilitas yang digunakan pada waktu penelitian dengan menggunakan suatu metode. Manfaat dari instrumen penelitian ini mempermudah pekerjaan peneliti dalam mengumpulkan data dan hasilnya pun lebih baik, dalam arti lebih cermat, lengkap, dan sistematis, sehingga mudah diolah. Instrumen yang digunakan untuk mengumpulkan data dalam penelitian ini menggunakan lembar observasi. Sugiyono (2011: 86) menyatakan secara umum "observasi dapat diartikan sebagai penghimpunan bahan-bahan keterangan yang diakukan dengan 
mengadakan pengamatan dan pencatatan secara sistematis terhadap berbagai fenomena yang dijadikan objek pengamatan". Adapun beberapa teknik kumite karate yang akan dianalisi adalah:

a) Kuda-Kuda salah satu gerakan dasar yang sangat penting, karena kuda-kuda merupakan tumpuan dari semua gerakan. Adapun jenis kuda-kuda yang akan dianalisis dalam kumite adalah hachijidachi, zen-kutsu-dachi, ko-kutsu-dachi, hangetsu-dachi, heisoku-dachi, neko-ashi-dachi, sanshindachi, sochin-dachi.

b) Pukulan (tsuki) adalah gerakan melakukan serangan dengan menggunakan tangan yang biasanya digunakan pada jarak dekat. Gerakan pukulan atau tsuki yang tak kalah pentingnya dengan kudakuda, karena pukulan sangat kita perlukan untuk menyerang lawan selain geri atau tendangan. Adapun jenis tendangan yang akan dianalisis adalah oi-zuki-chudan, oi-zuki-jodan, kisame-zuki, gyaku-zuki, ura-zuki, soto-ude-uke, morote-zuki, agi-zuki, choku-zuki, kage-zuki, yama-zuki morote-hisame-zuki, tetsui-uchi, uraken-uchi, haishu-uchi.

c) Tendangan (geri) adalah teknik menyerang lawan dalam karate bisa juga dengan mengunakan kaki dengan macam dan bentuk yang beragam sesuai dengan kebutuhan dan situasi yang dihadapi. Pada umumnya geri digunakan pada pertarungan dengan jarak yang tidak terlalu rapat. Adapun jenis tendangan yang akan dianalisis adalah mae-geri, mawashi-geri, yoko-geri-kekome, yoko-gerikeange, usiro-geri.

d) Tangkisan merupakan tindakan menghalangi serangan lawan dengan menggunakan tangan. Adapun teknik tangkisan yang terdiri dari gedan barai, soto-ude-uke, uchi-ude-uke, agi-uke, shutouke, juji-uke, morote-uke.

e) Pelanggaran merupakan tindakan tidak sesuai dengan aturan yang berlaku sehingga karateka diberikan hukuman karena tindakan tersebut. Adapun jenis hukuman yang diberikan pada karateka karena malakukan pelanggaran antara lain: (1) Chukoku merupakan hukuman yang diberikan bagi karateka yang melakukan pelanggaran ringan atau pelanggaran kecil yang dilakukan pertama kali. (2) Keikoku merupakan hukuman yang diberikan bagi karateka yang telah melakukan pelanggaran ringan dimana telah mendapatkan hukuman chukoku. (3) Hanshoku Chui merupakan peringatan yang diberikan setelah mendapat keikoku. Hukuman Hanshoku Chui dapat juga diberikan langsung manakala terjadi pelanggaran serius. (4) Hanshoku merupakan hukuman yang diterapkan seiring pelanggaran yang serius atau ketika hanshoku chui telah diberikan. Hal ini menghasilkan diskualifikasi (dikeluarkan dari pertandingan) dari kontestan. (5) Shikaku merupakan hukuman diskualifikasi dalam sebuah kejuaraan. Seperti karateka yang tidak dapat melanjutkan pertandingan karena cidera serius, mengabaikan perintah wasit, merusak prestise Karate-Do, telat datang setelah beberapa kali dipanggil ke arena.

Data yang akan dikumpulkan dalam penelitian ini yaitu teknik yang digunakan dalam karateka selama pertandingan kumite berlangsung. Adapun hasil dari pengumpulan data akan menghasilkan persentase keberhasilan dan juga kegagalan dari teknik yang digunakan berupa kuda-kuda, pukulan, tendangan dan juga tangkisan. Langkah-langkah atau proses pengambilan data dalam penelitian ini adalah sebagai berikut:

a. Peneliti mengidentifikasi atlet yang akan dijadikan sampel dalam penelitian ini yaitu pada Sea Games Ke-29 Tahun 2017 di Kuala Lumpur, Malaysia yaitu pada pertandingan final dibawah 55 Kg kategori Putra yaitu Iwan Bidu Sirait dari Indonesia dan Jhon Paul Bejar dari Philiphina. Sedangkan pada kategori putri dibawah $50 \mathrm{Kg}$ Srunita Sari Sukatendel Dari Indonesia dan Paweena Raksachart dari Thailand.

b. Peneliti melakukan pengamatan melalui rekaman video menggunakan aplikasi klip draw untuk menganlisis teknik-teknik dan pelanggaran yang dilakukan karateka selama pertandingan berlangsung.

c. Selanjutnya peneliti mengumpulkan data yang diperoleh dan melakukan transkrip atas hasil pertandingan.

d. Setelah memperoleh data penelitian, data diolah menggunakan analisis statistik berupa persentase keberhasilan dan kegagalan. Selain itu data yang diperoleh juga bisa menjumlahkan akumulasi penggunaan teknik yang digunakan selama pertandingan berlangsung.

e. Hasil dari analisis dilanjutkan dengan mengambil kesimpulan dan saran.

Analisis pertandingan dilakukan untuk memperoleh data yang tepat sehingga data tersebut dapat digunakan sebagai bahan evaluasi. Menurut Hasan (2004:29) bahwa analisis data adalah proses mengatur urutan data, mengorganisasikannya ke dalam suatu pola, kategori, dan satuan uraian dasar. 
Sedangkan Bogdan dan Taylor (2004: 29) menyatakan bahwa analisis data adalah proses yang merinci usaha formal untuk menemukan tema dan merumuskan hipotesis (ide) seperti yang disarankan oleh data dan sebagai usaha untuk memberikan bantuan pada tema dan hipotesis itu. Selanjutnya menurut Lexy J. Moleong (2004:29) analisis data adalah proses mengorganisasikan dan mengurutkan data ke dalam pola, kategori, dan satuan uraian dasar sehingga dapat dirumuskan hipotesis kerja, seperti yang disaran oleh data.

Dari kesimpulan beberapa ahli analisis data merupakan menguraikan atau memecahkan suatu keseluruhan menjadi bagian-bagian atau komponen-komponen yang lebih kecil agar dapat mengetahui komponen yang menonjol, membandingkan antara komponen yang satu dengan komponen lainnya. Analisa data yang digunakan dalam penelitian ini menggunakan statistik deskriptif kuantitatif dengan persentase. Perhitungan dalam analisis data menghasilkan persentase pencapaian yang selanjutnya diinterperstasikan dengan kalimat.

\section{HASIL DAN PEMBAHASAN}

\section{Hasil Analisis Kumite Karate Putra Dibawah $55 \mathrm{Kg}$}

Adapun hasil kesimpulan analisis pertandingan karate Sea Games Ke-29 Tahun 2017 di Kuala Lumpur, Malaysia yaitu final $\downarrow 55 \mathrm{Kg}$ dimana kuda-kuda (dachi) yang dilakukan oleh karateka Philipina John Paul Bejar adalah zenkutsu dachi sebanyak 334. Jumlah pukulan (tsuki) sebanyak 17 dengan jumlah perolehan point sebanyak 4 (24\%). Adapun pukulan (zuki) tersebut terdiri dari kizame zuki yaitu 1 pukulan dan tidak berhasil (0\%) sedangkan gyaku zuki terdiri dari 16 pukulan dengan 4 pukulan yang berhasil (25\%). Jumlah tendangan yang dilakukan selama pertandingan adalah 9 dimana tidak ada satupun tendangan yang menghasilkan point $(0 \%)$ adapun tendangan tersebut terdiri dari 6 tendangan mawashi geri, 1 tedangan uishiro mawashi geri dan tendangan ashi barai. Selama pertandingan tidak ada tangkisan yang dilakukan dimana hanya menghidari serangan yang dilakukan atau tidak melakukan kontak fisik untuk menangkis serangan. Adapun jumlah pelanggaran yang dilakukan karateka dari Philipina ini sebanyak 5 yang terdiri dari 2 hukuman chukoku, 2 hukuman keikoku, dan 1 hukuman hanshoki chui.

Tabel 1. Kesimpulan Analisis Pertandingan Kumite Karate Final $\downarrow 55$ Kg Kategori Putra Pada Sea Games Ke-29 Tahun 2017 di Kuala Lumpur, Malaysia

\begin{tabular}{|c|c|c|c|c|c|c|c|c|}
\hline $\begin{array}{l}\text { Negara: } \\
\text { Nama : } \\
\text { Kelas : }\end{array}$ & \multicolumn{2}{|c|}{$\begin{array}{l}\text { Philiphina } \\
\text { John Paul Bejar } \\
\text { Bellow } 55 \mathrm{Kg}\end{array}$} & 4 & $\begin{array}{c}\text { TEANIK } \\
\text { KUMITEKARATE }\end{array}$ & & $\begin{array}{r}\text { Iwan I } \\
\text { Bell }\end{array}$ & $\begin{array}{l}\text { ndonesia } \\
\text { idu Sirait } \\
\text { N } 55 \mathrm{Kg}\end{array}$ & $\begin{array}{c}\text { : Negara } \\
\text { : Nama } \\
\text { : Kelas }\end{array}$ \\
\hline \multicolumn{4}{|c|}{ Jumlah } & Kuda-Kuda & \multicolumn{4}{|c|}{ Jumlah } \\
\hline \multicolumn{4}{|c|}{334} & Zen-Kutsu-Dachi & \multicolumn{4}{|c|}{248} \\
\hline Jumlah & Point & Gagal & $\%$ & Pukulan & $\%$ & Gagal & Point & Jumlah \\
\hline 1 & $\mathrm{O}$ & 1 & $0 \%$ & Kisame-Zuki & $38 \%$ & 5 & 3 & 8 \\
\hline 16 & 4 & 12 & $25 \%$ & Gyaku-Zuki & $50 \%$ & 4 & 4 & 8 \\
\hline 17 & 4 & 13 & $24 \%$ & Jumlah & $44 \%$ & 9 & 7 & 16 \\
\hline Jumlah & Point & Gagal & $\%$ & Tendangan & $\%$ & Gagal & Point & Jumlah \\
\hline $\mathrm{O}$ & $\mathrm{O}$ & 0 & $0 \%$ & Mae Geri & $0 \%$ & 1 & 0 & 1 \\
\hline 6 & $\mathrm{O}$ & 6 & $2 \%$ & Mawashi Geri & $13 \%$ & 7 & 1 & 8 \\
\hline 1 & $\mathrm{O}$ & 1 & $0 \%$ & Ushiro Mawshi Geri & $0 \%$ & 1 & $\mathrm{O}$ & 1 \\
\hline O & $\mathrm{O}$ & 0 & $0 \%$ & Ushiro Ura Mawashi Geri & $0 \%$ & 1 & 0 & 1 \\
\hline 2 & $\mathrm{O}$ & 2 & $0 \%$ & Ashi Barai & $0 \%$ & 2 & 0 & 2 \\
\hline 9 & $\mathrm{O}$ & 9 & $1 \%$ & Jumlah & $8 \%$ & 12 & 1 & 13 \\
\hline Jumlah & Point & Gagal & $\%$ & \multirow{2}{*}{ Tangkisan } & $\%$ & Point & Gagal & Jumlah \\
\hline 0 & 0 & 0 & 0 & & 0 & 0 & 0 & 0 \\
\hline \multicolumn{4}{|c|}{ Jumlah } & Pelanggaran & \multicolumn{4}{|c|}{ Jumlah } \\
\hline \multicolumn{4}{|c|}{2} & Chukoku & \multicolumn{4}{|c|}{2} \\
\hline \multicolumn{4}{|c|}{2} & Keikoku & \multicolumn{4}{|c|}{2} \\
\hline \multicolumn{4}{|c|}{1} & Hanshoki Chui & \multicolumn{4}{|c|}{1} \\
\hline \multicolumn{4}{|c|}{0} & Hanshoku & \multicolumn{4}{|c|}{$\mathrm{O}$} \\
\hline \multicolumn{4}{|c|}{5} & Jumlah & \multicolumn{4}{|c|}{5} \\
\hline
\end{tabular}

Karateka dari Indonesia yaitu Iwan Bidu Sirait melakukan kuda-kuda zenkutsu dachi sebanyak 248. Jumlah pukulan (tsuki) sebanyak 16 dengan jumlah perolehan point sebanyak 7 (44\%). Adapun 
pukulan (zuki) tersebut terdiri dari kizame zuki yaitu 8 pukulan dan 3 pukulan yang menghasilkan point (38\%) sedangkan gyaku zuki terdiri dari 8 pukulan dengan 4 pukulan yang berhasil (50\%). Jumlah tendangan yang dilakukan selama pertandingan adalah 13 dimana terdapat satu tendangan yang menghasilkan point (8\%). Adapun tendangan tersebut terdiri dari 1 tendangan mae geri dan tidak menghasilkan point (0\%), 8 tendangan mawashi geri dimana hanya 1 tendangan yang dapat menghasilkan point (13\%), 1 tedangan uishiro mawashi geridan dimana tidak menghasilkan point (0\%), 1 tedangan uishiro Ura mawashi geri dimana tidak menghasilkan point (0\%), dan 2 tendangan ashi barai dan tidak menghasilkan point $(0 \%)$. Selama pertandingan tidak ada tangkisan yang dilakukan dimana hanya menghidari serangan yang dilakukan atau tidak melakukan kontak fisik untuk menangkis serangan. Adapun jumlah pelanggaran yang dilakukan karateka dari Philipina ini sebanyak 5 yang terdiri dari 2 hukuman chukoku, 2 hukuman keikoku, dan 1 hukuman hanshoki chui.

Adapun hasil pertandingan dimenangkan oleh Iwan Bidu Sirait dari Indonesia dengan perolehan point sebanyak 10 yang terdiri dari 7 pukulan dan 1 tendangan. Adapun jumlah pukulan yang dilakukan selama pertandingan adalah 16 dengan 7 pukulan yang menghasilkan point sehingga persentase keberhasilan pukulannya adalah $44 \%$. Tendangan yang dilakukan selama pertandingan sebanyak 14 dengan 1 tendangan yang menghasilkan point sehingga persentase keberhasilan tendangannya adalah 8\%. Sedangkan John Paul Bejar dari Philpina menghasilkan point sebanyak 4 yang semuanya dihasilkan oleh pukulan. Adapun jumlah pukulan yang dilakukan selama pertandingan adalah 13 dengan persentase keberhasilan 24\%. Sedangkan jumlah tendangan yang dilakukan adalah 9 dimana tidak ada menghasilkan point atau persentase keberhasilannya adalah $0 \%$.

\section{Hasil Analisis Kumite Karate Putri Dibawah $50 \mathrm{Kg}$}

Adapun kesimpulan hasil analisis pertandingan Kumite Karate Final dibawah $50 \mathrm{Kg}$ Kategori Putri Pada Sea Games Ke-29 Tahun 2017 di Kuala Lumpur, Malaysia adalah sebagai berikut:

Tabel 2. Kesimpulan Analisis Kumite Karate Final dibawah 50 Kg Kategori Putri Pada Sea Games Ke-29 Tahun 2017 di Kuala Lumpur, Malaysia

\begin{tabular}{|c|c|c|c|c|c|c|c|c|}
\hline \multicolumn{3}{|c|}{$\begin{array}{l}\text { Negara : Thailand } \\
\text { Nama: } \quad \text { Paweena Raksachart } \\
\text { Kelas: } \quad \text { Bellow } 50 \mathrm{Kg}\end{array}$} & 0 & $\begin{array}{c}\text { TEANIK } \\
\text { KMITEKARATE }\end{array}$ & 1 & Srunita S & $\begin{array}{r}\text { Indone } \\
\text { Sukatend } \\
\text { llow } 50 \\
\end{array}$ & $\begin{array}{r}\text { : Negara } \\
\text { : Nama } \\
\text { : Kelas }\end{array}$ \\
\hline \multicolumn{4}{|c|}{ Jumlah } & Kuda-Kuda & \multicolumn{4}{|c|}{ Jumlah } \\
\hline \multicolumn{4}{|c|}{212} & Zen-Kutsu-Dachi & \multicolumn{4}{|c|}{221} \\
\hline \begin{tabular}{|l|} 
Jumlah \\
\end{tabular} & Point & Gagal & $\%$ & Pukulan & $\%$ & Gagal & Point & Jumlah \\
\hline 13 & 0 & 13 & $0 \%$ & Kizame-Zuki & $29 \%$ & 5 & 2 & 7 \\
\hline 6 & 0 & 6 & $0 \%$ & Gyaku-Zuki & $17 \%$ & 5 & 1 & 6 \\
\hline 19 & 0 & 19 & $0 \%$ & Jumlah & $19 \%$ & 10 & 3 & 13 \\
\hline \begin{tabular}{|l|} 
Jumlah \\
\end{tabular} & Point & Gagal & $\%$ & Tendangan & $\%$ & Gagal & Point & Jumlah \\
\hline--- & --- & --- & --- & Mae Geri & --- & --- & --- & --- \\
\hline 3 & 0 & 3 & $0 \%$ & Mawashi Geri & $0 \%$ & 5 & 0 & 5 \\
\hline 1 & 0 & 1 & $0 \%$ & Ushiro Mawshi Geri & $33 \%$ & 2 & 1 & 3 \\
\hline 4 & 0 & 4 & $0 \%$ & Ushiro Ura Mawashi Geri & $0 \%$ & 0 & 0 & 0 \\
\hline 0 & 0 & 0 & $0 \%$ & Ashi Barai & $0 \%$ & 1 & 0 & 1 \\
\hline 8 & 0 & 8 & $0 \%$ & Jumlah & $11 \%$ & 8 & 1 & 9 \\
\hline \begin{tabular}{|l|} 
Jumlah \\
\end{tabular} & Point & Gagal & $\%$ & Tangkisan & $\%$ & Point & Gagal & Jumlah \\
\hline 0 & 0 & 0 & 0 & Jumlah & 0 & 0 & 0 & 0 \\
\hline \multicolumn{4}{|c|}{ Jumlah } & Pelanggaran & \multicolumn{4}{|c|}{ Jumlah } \\
\hline \multicolumn{4}{|c|}{2} & Chukoku & \multicolumn{4}{|c|}{2} \\
\hline \multicolumn{4}{|c|}{2} & Keikoku & \multicolumn{4}{|c|}{2} \\
\hline \multicolumn{4}{|c|}{1} & Hanshoki Chui & \multicolumn{4}{|c|}{0} \\
\hline \multicolumn{4}{|c|}{1} & Hanshoku & \multicolumn{4}{|c|}{0} \\
\hline \multicolumn{4}{|c|}{6} & Jumlah & \multicolumn{4}{|c|}{4} \\
\hline
\end{tabular}

Kuda-kuda (dachi) yang dilakukan oleh karateka Putri dari Thailand Paweena Raksachart adalah zenkutsu dachi sebanyak 212. Jumlah pukulan (tsuki) sebanyak 19 dengan tidak ada perolehan point dari pukulan tersebut $(0 \%)$. Jumlah tendangan yang dilakukan selama pertandingan adalah 8 dimana tidak ada satupun tendangan yang menghasilkan point $(0 \%)$ adapun tendangan tersebut terdiri 
dari 3 tendangan mawashi geri, 1 tendangan uishiro mawashi geri dan 1 tendangan uishiro ura mawashi geri. Selama pertandingan tidak ada tangkisan yang dilakukan dimana hanya menghidari serangan yang dilakukan atau tidak melakukan kontak fisik untuk menangkis serangan. Adapun jumlah pelanggaran yang dilakukan karateka putri dari Thailand ini sebanyak 6 yang terdiri dari 2 hukuman chukoku, 2 hukuman keikoku, 1 hukuman hanshoki chui dan 1 hukuman hanshoku.

Karateka Putri dari Indonesia yaitu Srunita Sari Sukatendel melakukan kuda-kuda zenkutsu dachi sebanyak 221. Jumlah pukulan (zuki) sebanyak 13 dengan jumlah perolehan point sebanyak 3 (19\%). Adapun pukulan (zuki) tersebut terdiri dari kizame zuki yaitu 7 pukulan dan 2 pukulan yang menghasilkan point (29\%) sedangkan gyaku zuki terdiri dari 6 pukulan dengan 1 pukulan yang menghasilkan point (19\%). Jumlah tendangan yang dilakukan selama pertandingan adalah 9 dimana terdapat satu tendangan yang menghasilkan point (11\%). Adapun tendangan tersebut terdiri dari 5 tendangan mawashi geri dan tidak menghasilkan point (0\%), 3 tendangan ushiro mawashi geri dimana hanya 1 tendangan yang dapat menghasilkan point (33\%) dan 1 tendangan ashi barai dan tidak menghasilkan point $(0 \%)$. Selama pertandingan tidak ada tangkisan yang dilakukan dimana hanya menghidari serangan yang dilakukan atau tidak melakukan kontak fisik untuk menangkis serangan. Adapun jumlah pelanggaran yang dilakukan karateka dari Indonesia sebanyak 4 yang terdiri dari 2 hukuman chukoku, 2 hukuman keikoku, sedangkan hukuman hanshoki chui dan hanshoku tidak ada.

Adapun hasil pertandingan dimenangkan oleh Srunite Sari Sukatendel karateka putri dari Indonesia dengan perolehan point sebanyak 6 yang terdiri dari 3 pukulan dan 1 tendangan adapun jumlah pukulan yang dilakukan selama pertandingan berlangsung adalah 13 dengan 3 pukulan yang dapat menghasilkan point adapun persentase keberhasilan adalah $19 \%$ sedangkan jumlah tendangan yang dilakukan adalah 9 dan hanya 1 tendangan yang menghasilkan point dengan persentase keberhasilan $11 \%$. Sedangkan Paweena Raksachart Karateka Putri dari Thailand tidak menghasilkan point selama pertandingan berlangsung. Terdapat 19 pukulan yang dilakukan dan 8 tendangan dimana tidak satupun yang dapat menghasilkan point.

\section{SIMPULAN}

Dari hasil analisis yang dilakukan terhadap hasil pertandingan Karate Sea Games Ke-29 Tahun 2017 di Kuala Lumpur, Malaysia pada kategori final putra $\downarrow 55 \mathrm{Kg}$ adalah Iwan Bidu Sirait dari Indonesia dan Jhon Paul Bejar dari Philiphina. Sedangkan pada kategori final putri $\downarrow 50 \mathrm{Kg}$ Srunita Sari Sukatendel Dari Indonesia dan Paweena Raksachart dari Thailand maka diperoleh kesimpulan sebagai berikut:

1. Pada kategori final putra dibawah $55 \mathrm{~kg}$ pertandingan dimenangkan oleh Iwan Bidu Sirait dari Indonesia dengan perolehan point sebanyak 10 yang terdiri dari 7 pukulan dan 1 tendangan. Adapun jumlah pukulan yang dilakukan selama pertandingan adalah 16 dengan 7 pukulan yang menghasilkan point sehingga persentase keberhasilan pukulannya adalah $44 \%$. Tendangan yang dilakukan selama pertandingan sebanyak 14 dengan 1 tendangan yang menghasilkan point sehingga persentase keberhasilan tendangannya adalah 8\%. Sedangkan John Paul Bejar dari Philpina menghasilkan point sebanyak 4 yang semuanya dihasilkan oleh pukulan. Adapun jumlah pukulan yang dilakukan selama pertandingan adalah 13 dengan persentase keberhasilan $24 \%$. Sedangkan jumlah tendangan yang dilakukan adalah 9 dimana tidak ada menghasilkan point atau persentase keberhasilan tendangan tersebut adalah $0 \%$.

2. Pada kategori final putri $\downarrow 50 \mathrm{~kg}$ hasil pertandingan dimenangkan oleh Srunita Sari Sukatendel karateka putri dari Indonesia dengan perolehan point sebanyak 6 yang terdiri dari 3 pukulan dan 1 tendangan adapun jumlah pukulan yang dilakukan selama pertandingan berlangsung adalah 13 dengan 3 pukulan yang dapat menghasilkan point adapun persentase keberhasilan adalah 19\% sedangkan jumlah tendangan yang dilakukan adalah 9 dan hanya 1 tendangan yang menghasilkan point dengan persentase keberhasilan 11\%. Sedangkan Paweena Raksachart Karateka Putri dari Thailand tidak menghasilkan point selama pertandingan berlangsung. Terdapat 19 pukulan yang dilakukan dan 8 tendangan dimana tidak satupun yang dapat menghasilkan point atau persentase keberhasilannya adalah $0 \%$.

Dari hasil penelitian yang dilakukan diperoleh saran yang dapat digunakan oleh pelatih dan karateka yaitu: 
1) Dalam pertandingan kumite karate kuda-kuda yang digunakan adalah zenkutchu dachi dimana hal ini menjadi memberikan kemudahan bagi karateka karena dapat dengan dinamis bergerak baik pada saat bertahan dan menyerang. Hasil penelitian ini menjadi panduan untuk pelatih agar meningkatkan kemampuan kuda-kuda zenkutchu dachi karateka jika akan mengikuti pertandingan kumite.

2) Pukulan menjadi teknik yang paling banyak menghasilkan point. Adapun jenis pukulan yang paling sering digunakan adakah kizame zuki dan gyaku zuki. Pukulan ini sering digunakan karateka karena kecepatannya dalam melakukan gerakan ini dimana pukulan dilakukan lurus ke depan sehingga baik pada saat bertahan dan menyerang pukulan ini sangat efektif digunakan. Kepada pelatih karate agar meningkatkan kemampuan pukulan kizame zuki dan gyaku zuki sehingga karateka dapat melakukan gerakan pukulan ini lebih baik pada saat mengikuti pertandingan kumite.

3) Tendangan adalah salah satu teknik yang sangat jarang menghasilkan point dimana gerakannya yang mudah dibaca oleh lawan sehingga lebih mudah di hindari atau ditangkis menggunakan tangan maupun kaki. Tetapi beberapa karateka yang sudah terlatih dapat memanfaatkan situasi untuk melakukan tendangan yang dapat menghasilkan point. Dengan demikian pelatih karateka juga harus tetap melatih seluruh jenis tendangan karena dapat digunakan dengan tepat pada saat pertandingan sehingga dapat menghasilkan point.

\section{DAFTAR PUSTAKA}

Arikunto Suharsimi (2010) Prosedur Penelitian. Jakarta: PT Asdi Mahasatya.

Bogdan dan Taylor. (2004). Metodologi Penelitian Kualitatif. Bandung: Remadja Karya

Chung- Yu Chen \& Huang Chenfu. (2008). Biomechanical analysis of straight and flexural leg swings of the Chinese Martial Arts jumping front kick. Taipei: National Taiwan Normal University.

Ferry Fendrian; Muhammad Nurzaman, (2016). Efektivitas Teknik Serangan Pukulan Dan Teknik Serangan Tendangan Terhadap Perolehan Poin Dalam Pertandingan Kumite Cabang Olahraga Karate, Jurnal Kepelatihan Olahraga, Volume 8, No. 2 Desember 2016.

Moleong, Lexy J. (2007). Metodologi Penelitian Kualitatif. Bandung: PT. Remaja Rosdakarya.

Nakayama, M (2010). Best Karate Comprehensive; Terjemahan; Bambang Oriyanto; Jakarta: The Modul Inkai Laboratory.

PB. FORKI. (2012). Buku Peraturan Pertandingan Karate. Jakarta: PB FORKI.

Prihastono, A. (1995). Pembinaan Kondisi Fisik Karate. Jakarta: CV Aneka.

Sugiyono (2011) Metode Penelitian Kuantitatif, Kualitatif, dan R\&D, Bandung: CV Alfabeta

Sujoto J.B. (2002). Teknik Oyama Karate Seri Kihon. Jakarta: Elek Media Komputindo. 